\title{
The Benefits and Impact of Digital Twins in Product Development Phase of PLM
}

\author{
Ilkka Donoghue ${ }^{1}$, Lea Hannola ${ }^{1}$, Jorma Papinniemi $^{1}$ and Aki Mikkola ${ }^{2}$ \\ ${ }^{1}$ Industrial Engineering and Management, \\ ${ }^{2}$ Mechanical Engineering, \\ Lappeenranta University of Technology \\ PL 20, FI-53851 Lappeenranta, Finland \\ ilkka.donoghue@lut.fi; lea.hannola@lut.fi; jorma.papinniemi@lut.fi;
} aki.mikkola@lut.fi

\begin{abstract}
The concept of the Digital Twins offers opportunities for business-tobusiness (B2B) manufacturing companies to co-create and maintain Product-Service-Systems. This facilitates closer relationship with customers over the lifespan of the delivered solution. However, the definition of the Digital Twin is not yet established in the companies that took part in this research that forms the basis to understand the relationship between the Digital Twins and Product-Service-Systems.
\end{abstract}

The objective of this paper is to define the concepts of Digital Twin and real-time simulation, and increase understanding of the benefits and impacts that B2B companies face when applying real-time simulation, and understand where the transformation should start in Product Lifecycle Management. The case companies that participated in this research are mobile work machine manufactures, but the findings are applicable to other B2B manufacturing companies which have complex solution deliveries that are managed over the lifecycle.

Results of this study show that B2B manufacturing companies are using real-time simulation to create digital twins of their real-world solutions. The companies participating in the research project create functioning digital twins but managing them is tedious and not integrated to the Product Lifecycle Management operations. First, only applying this to product development is not enough, but the management must cover the entire lifecycle of the product from Beginning (BOL), Middle (MOL) and End-of-Lifecycle (EOL). Second, the need to rethink the approach to product development and management is a key for success. Otherwise, the result is a virtual representation of the real world that is impossible to maintain at industrial level.

Keywords: Digital Twin, Real-time Simulation, Product Lifecycle Management, PLM, Product-Service system, Digital Mock-Up. 


\section{$1 \quad$ Introduction}

The focus of this paper is to increase understanding how digital twins, especially built on real-time simulation, impact and create benefits already in the product development phase. This paper increases understanding for B2B companies when applying real-time simulation based digital twins, and to understand how the transformation should start in Product Lifecycle Management (PLM). The integration of the Digital Twin and PLM is becoming important to B2B companies. To understand the benefits and limitations to the products, services, and ways of working, requires understanding of the different elements defining the digital twin. However, agreement what a digital twin is depends on the audience. In simplicity, it can just be the meta data that describes the product or as a complex real-time IoT-based simulation model. The Digital Mock-Up (DMU) is closely related concept to the digital twin and they have similarities. Typically, the DMU is a 3D definition of the product over its lifecycle. However, here the digital twin is connected to the physical world representation (via IoT) and is able to integrate machine learning to improve its operations and its real-world counterpart over the lifecycle. In addition, it can simulate, in real-time the multibody dynamics of the real-world counterpart throughout the lifecycle. For product development, this means that the digital twin is developed as a real-world counterpart and integrated to it once it is delivered. This paper tries to understand, through two case companies, the relationship between the digital twin and real-time simulation in the product development and management phase of PLM.

Fig. 1 (A) presents the current way digital tools are used in the existing organisations. Typically, real-time simulation is a practice that is managed in product development or is used for training purposes instead of being a transparent value-add process to benefit the users or customers. Currently, this slows feedback from users and the overall development process. In addition, actual errors or shortcomings can occur in new products. Fig. 1 (B) disrupts the existing working ways in the case companies by bringing the users part of the product development process instigating a co-creation environment which is built on the real-time simulation in a real-time co-creation environment. This approach could shorten the development times and increase user and customer satisfaction creating a positive customer experience. (Mikkola, et al., 2014)

A)

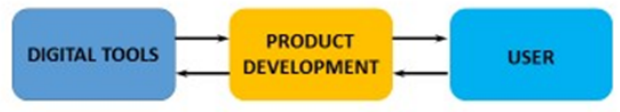

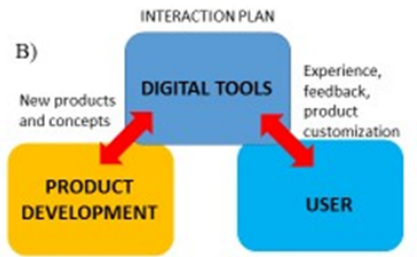

Fig. 1: Real-time Simulation can offer ways co-develop product and services with customers creating disruption in the traditional product development operations (Mikkola et al., 2014) 
The relevance of digital twins is growing in manufacturing companies and the opportunities to create new business models based on services is increasing. The current understanding is that there are multiple elements that influence the digital twin. Research has been published on the key elements, but they have not been integrated into a concept where the different elements are organized in a framework to use in manufacturing business. The underlining question is the relationship of real-time simulation and digital twins in creating value and minimizing disruption for manufacturing companies over the lifecycle.

\section{$2 \quad$ Related Research}

The research on the key elements that constituent the digital twin in PLM have be reviewed in the following. The objective is to understand the relationship, if exist, of these different elements for the research carried out with the case companies.

\subsection{Digital Twin}

The Digital Twin is not a new concept and it can be seen part of the Product Lifecycle Management (PLM) vision (Grieves, 2006). The Digital Twin can be defined according to Bilello (2017, pp. 9) as "Digital surrogate (i.e., the Digital Twin) is a physics-based description of the system resulting from the generation, management, and application of data, models, and information from authoritative sources across the system's lifecycle". The Digital Twin is at the core of digitalization and is based on the use of digital technologies. However, the usability and maintenance of the virtual product over the lifecycle has not been efficient with traditional metadata and structure-based definitions of products. The Digital Twin must consist of the virtual product and the virtual process definition, and most importantly it requires end-to-end connectivity and physics-based simulation. When this alignment is achieved, the Digital Twin can create new business models that provide new revenue, value propositions and business opportunities to companies. (Bilello, 2017)

A complete Digital Twin representation consists of four elements that are (1) real space, (2) virtual space, (3) the data link from real space to virtual space, (4) and information link from virtual space to real space and virtual sub-spaces (refers to one or more digital representation of the product). A physical product operates in real space whereas a virtual machine (i.e. simulation model) is created in virtual space. A virtual machine can be constructed using a multibody simulation. With this approach, it is possible to build detailed physics-based simulation model to analyse dynamics of complex products such like a mobile machine.

\subsection{Product Lifecycle Management}

There is a variety of related concepts and definitions in the literature on Product Lifecycle Management (PLM), depending on the focus of the authors. According to Stark 
(2018), PLM is the business activity of managing, in the most effective way, a company's products all the way across their lifecycles; from the very first idea for a product all the way through until it is retired and disposed of. From the executive's point of view, PLM is the management system for the company's products.

In context, Product Lifecycle Management is an integrative information-driven approach comprised of people, processes/practices, and technology to all aspects of a product's life and its environment, from its design through manufacture, deployment and maintenance. Product Data Management (PDM) is a systematic, directed set of tools by which to manage and develop an industrially manufactured product. Information systems of PDM and with wider frame-oriented PLM systems are based on data model, enable accessing, updating, manipulating and reasoning about product information that is being produced in a fragmented and distributed environment (Grieves 2006, Saaksvuori et al. 2008). The required capabilities on PLM systems are for example product data and structure management and data exchange of Computer-Aided Design (CAD) models (Siller et al. 2008).

Product knowledge management throughout the lifecycle of the product and the related services has attracted increasing consideration in research and (mainly manufacturing) company practices in recent years. New digital tools and solutions, e.g. Internet of Things, Virtual Reality, Digital twins and simulation, for managing product related data and information across lifecycles, enable new kind of smart services and productservice systems.

\subsection{Product-Service-Systems}

The term Product-Service-Systems (PSS) has been gaining attention from research and industry in recent years, which takes the "Servitization" approach of manufacturing companies of switching from a physical product-based business to a service-oriented strategy (Verdugo Cedeño et al., 2018). Tukker and Tischner (2006) define PSS as " $a$ specific type of value proposition that a business network offers to or co-produces with its clients, and it consists of a mix of tangible products and intangible services designed and combined so that they jointly are capable of fulfilling final customer needs". According to Tukker and Tischner, the PSS concept focuses on the following two pillars:

1. Taking the final functionality that the user wants as a starting point of business development (instead of the product fulfilling this functionality)

2. Expanding the system that provides this functionality with a 'greenfield' mindset (instead of taking existing structures, routines and the position of the own company therein for granted).

Xin et al. (2017) have made a systematic literature review of empirical PSS studies between 2006 and 2016, and they found that PSS practices are widely applied across different research and geographical areas. In addition, the PSS studies indicate that the evolution of PSS is still in its early development stage (Xin et al., 2017). 


\subsection{Multibody Real-time Simulation}

Multibody real-time simulation techniques have enabled the precise description of complex mechanical systems such as mobile and industrial machinery and the subsequent solution of the relevant equations of motion in real time. This capability has been available for more than three decades. Currently, real-time simulation models based on multibody dynamics can account for a large number of rigid [Garcia de Jalon et al., 1994] and flexible bodies [Garcia de Jalon et al., 1994], and contact models [Garcia de Jalon et al., 1994]. These multibody-based approaches can be combined with models of actuators enabling the description of multi-physical systems as the one shown in Figure Fig. 2.

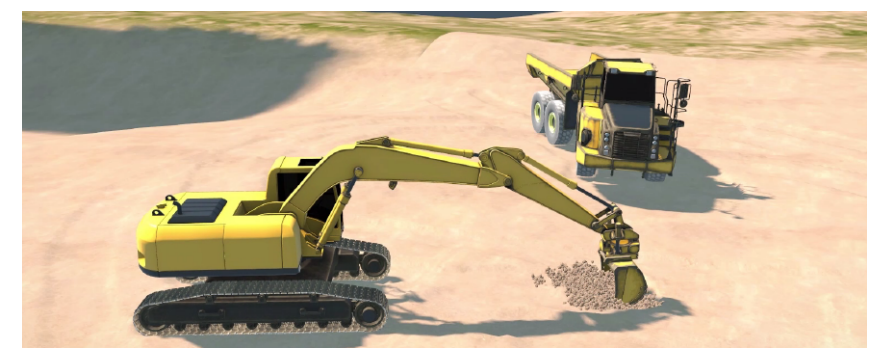

Fig. 2:. An excavator model operating on deformable ground

\section{$3 \quad$ Research Process}

The research process applied design science research approach (Hevner, 2004; Hevner, 2007 ) and data collection was made through semi-structured interviews. These methods were selected based on the goal to understand what is the current state of the case companies and provide insights on how to bring value to the case companies. The case companies that participated in this research are mobile work machine manufactures. To maintain anonymity, the companies are referred to company Ox-cart and Have-Blue. Ox-cart provides intelligent mobile material handling solutions and services and HaveBlue provides vehicles, service and solutions to the mining and construction industry.

The research was divided into two phases; (1) the first to understand the as-is status of product development and management in the companies, and (2) impacts and benefits in the transformation towards the future state when digital twins and real-time simulation is applied into practice. The research focus was on the application of real-time simulation. The research method was divided into the following phases:

1. Review into related research to understand previously published concepts that impact the research area. A superficial review of social media was also done. 
2. Interview the case companies' product development and product management representatives to understand the as-is state and opportunities and impacts when applying digital twins.

3. Identify possible business benefits and impact on current product development and management.

\section{$4 \quad$ Benefits and Impacts of the Digital Twin}

The results can be divided into benefits that improve the way of working and the impact that a digital twin has on the product development and PLM. The adoption of real-time simulation, that forms the digital twin, requires a change in the way companies execute product development and PLM in future. Based on the work carried out with companies, the digital twin is a feasible option when it is full physics based realtime simulation. However, the maturity level of the two companies are different. Company Ox-cart has piloted digital twins based on real-time simulation in product development but are still evaluating the business case for full implementation across the company's operations. However, the first area of implementation is product development. On the other hand, Company Have-Blue have implemented and are using realtime simulation-based digital twins in certain product lines. This implementation has focused on product development and management, but it has also been piloted in other areas for example sales and manufacturing. Common benefits are closer customer relationship and dialogue that enables faster product development. This need for transparent communication with customers is not often present in product development. The main goals for the case companies from real-time simulation based digital twins are:

- Improved R\&D and Product Management Processes improving efficiency and cost.

- Better understanding of customer needs with co-creation during development.

- New Product-Service-System (PSS) possibilities due to integration of operations data and connected digital twins (virtual-PSS).

Both case companies' product and service portfolios are diverse and the customer segments that they support are heterogeneous. Each product and service line have different needs and maturity levels. The Have-Blue portfolios consist of, for example, software, automation, equipment and process solutions that from product-service-systems. The companies use traditional simulation in the product development processes and have also invested in real-time simulation solutions. A key issue for real-time simulation is the need for specialised expertise, and the effort to manage complex models. The opinion is that benefits can be achieved if the productization of real-time simulation software is improved and the code development is replaced with ready user interfaces. Building a re-useable library of simulation products, modules and services across or in product platforms is key for adoption in these companies. As an example, a re-usable module is a control logic used in the drive system or the boom. 
Table 1. positions the different simulation dimensions that exist and identifies the simulation areas where value could be brought to product development and management in the companies. The goal of Table 1 was to create insight what is the as-is and vison for real-time simulation driven digital twins. In Table 1, the columns represent the different simulation domains that were identified in the case companies. The Simulation Column covers traditional simulation methods used by most companies. These include, for example, CFD of FEM simulations. The Realtime Simulation Column covers the full physics real-time simulation which is an accurate physics-based representation of the mobile work machines, e.g., excavator. The $3^{\text {rd }}$ column Collaborative Realtime Simulation uses real-time simulation, but in a virtual environment that enables the simultaneous use of multiple real-time simulation models where the environment is a real-time simulation, for example, mine, airport or harbour, and are cloud based. The Faster than Realtime Column represents real-time simulations where the simulations can be carried out faster than the real-world occurrence.

The rows represent the different simulation approaches. The $1^{\text {st }}$ row Virtual Reality represents the model where human interaction is not present. The $2^{\text {nd }}$ row Human in the $V R$ loop is controlled and operated by a human. The $3^{\text {rd }}$ line Hardware in the VR loop is when the digital twin has a real-world element connected to it or vice versa. The $4^{\text {th }}$ line Data in-the-loop is when the simulations are run based on real-time data collected from Product-Service-System. The $5^{\text {th }}$ line Augmented Reality is when the digital information is shown in the real world in real-time. Line 6 and Line 7 represent Artificial Narrow (ANI) and General (AGI) Intelligence where the simulation model can make different levels of decisions independently with or without operational data. Line 8 is when Artificial Super Intelligence is in the loop. AGI and ASI are visions only. The vision is to apply Narrow AI to the connected system, but the basics must be in place first. ANI with degrees of autonomy has interesting possibilities in connected digital twin and PSS.

Table 1 Digital Twin domains and simulation approaches. Green areas are under development and blue areas are concepts of interest to the case companies

\begin{tabular}{|l|c|c|c|c|}
\hline Digital Twin & Simulation & $\begin{array}{c}\text { Realtime } \\
\text { Simulation }\end{array}$ & $\begin{array}{c}\text { Collaborative } \\
\text { Realtime } \\
\text { Simulation }{ }^{1}\end{array}$ & $\begin{array}{c}\text { Faster than } \\
\text { Realtime Simu- } \\
\text { lation }\end{array}$ \\
\hline $\begin{array}{l}\text { Virtual Reality } \\
\text { model }\end{array}$ & Used & Limited use & Not in use & Used \\
\hline $\begin{array}{l}\text { Human in the VR } \\
\text { loop }\end{array}$ & Used & Limited use & Not in use & Concept \\
\hline $\begin{array}{l}\text { Hardware in the } \\
\text { loop }\end{array}$ & Used & Limited use & Not in use & Concept \\
\hline Augmented reality & Used & Not in use & Not in use & Concept \\
\hline ANI in the loop & N/A & Concept & Vision & Vision \\
\hline AGI in the loop & N/A & Vision & Vision & Vision \\
\hline ASI in the loop & N/A & Vision & Vision & Vision \\
\hline N/A = Not Applicable & \multicolumn{3}{|l}{} \\
\hline
\end{tabular}


The case companies use different simulation and IT tools to create the digital twin. However, the simulation solutions are used interpedently in product development and PLM. The case companies use real-time simulation, but it is not fully integrated to the Enterprise Architecture (EA) and is difficult to maintain meaning few true digital twins based on real-time simulation exist.

The implementation of digital twins impacts the architecture of the case companies because it changes how the companies manage product development processes and involve external and internal stakeholders. The real-time simulation maturity level in the architecture areas were:

- Specialist exist in organisations (Organisation Architecture and Role Descriptions)

- Realtime simulation and digital twin not integrated to process (Process Architecture)

- Realtime simulation models built from scratch (Information Architecture)

- Realtime simulation not integrated to Information System (IS architecture).

However, if implemented as part of the enterprise architecture, real-time simulation and therefore digital twins will improve the product development and management processes reducing cost through faster feedback and earlier involvement of the customer in the development phase. The case companies' objectives were to understand how realtime simulation can bring value and to create a business case for the digital twin. The interviews uncovered benefits and pains in product development and PLM that realtime simulation can improve. These most important areas, based on the interviews with the companies were:

- Time-to-Market can be reduced with real-time simulation.

- Improved marketing \& sales of new PSS capabilities and features to customer.

- Collecting end-user and customer feedback and needs.

- Building concepts and prototypes to get customer insight faster at lower cost.

- Release time between prototypes after testing feedback can be reduced.

- Replacing time consuming and costly product testing with real-time simulationbased.

- Threshold to start new product development does not need significant drop in sales (especially company Ox-cart).

- Deeper view how services are used and integrated in customer PSS.

In both companies, product development time must be reduced in the future and getting it first-time right is critical for success, as is cost. In Ox-Cart, the key elements for equipment success is operator visibility, driving and loading experience. These areas can be developed faster with real-time simulation with the near real-world operator experience. Realtime simulation was used to collect operator feedback on improvements e.g. maintenance procedures and accessibility. For Have-Blue, the integration of the digital twin to products can create an augmented real-time simulation to test and verify improvements to the product. This data was used to understand the traditional asset-based service's needs. The time and cost to build new real-world prototypes is a 
risk that impacts internal and supplier resources. Using a configurable real-time simulation models, in the early stage of development for prototyping, enabled customer feedback and improved requirement collection in early stages of development. The suppliers develop and deliver more than half of the assemblies in the products and many of these assemblies are developed at the same time as the end-product. If a digital twin is used, the possibility to test, e.g. control software, would ensure quicker development cycles and identify supplier errors early in the development phase. Real-time simulation, if is used for testing and certification, would reduce physical prototypes.

\section{Discussion and Conclusions}

Digital Twins are not only tools for product development to gain better customer commitment to new concepts. The real opportunities lie in creating digital products and services that integrate the real and digital worlds together and form a connected solution (Fig. 3). If a real-time simulation based digital twin is implemented, this digital representation can change the way companies view their products and services in the future. The virtual product becomes the asset that opens new business opportunities, for example, connected information-based services. This enables the creation of Product-Service-Systems (PSS) that can be used to simulate the PSS different lifecycle phases.

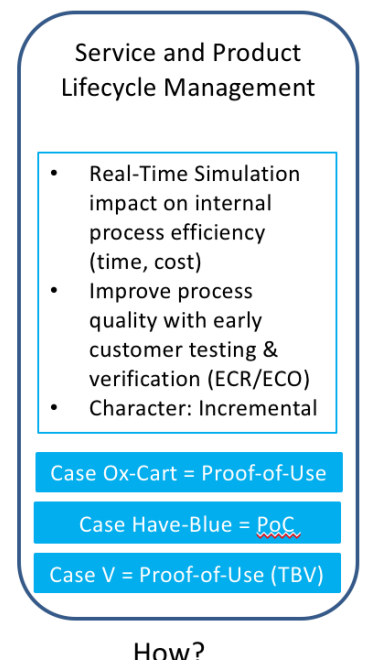

How?

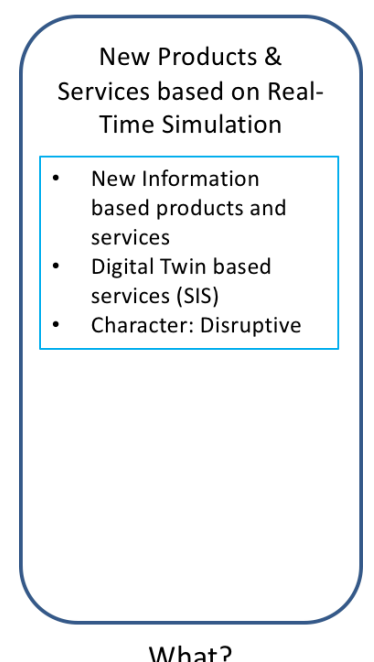

What?

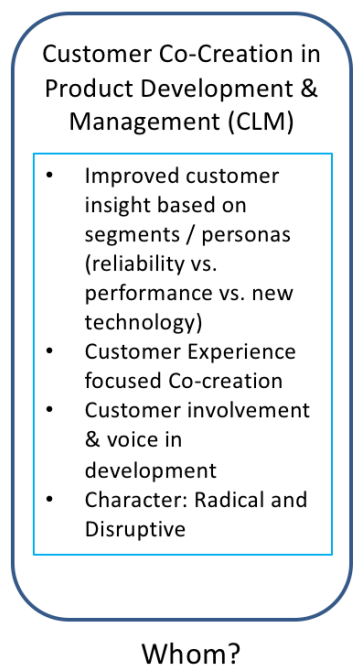

Whom?

Fig. 3:. Digital Twin high-level benefits achievable through application of Real-Time Simulation when connected to real-world counterpart

The digital twin concept impacts the case company core from R\&D to install base management. The value comes from the lifecycle management of PSS where the connected product can provide information to the digital twin. This information can verify 
the real-time simulation accuracy but can form the basis to continuously test new development and operational scenarios. Therefore, real-time simulation based digital twins can create a digital-PSS with predictive services in the form of product efficiency services, customer process support, and process delegation services.

For real-time simulation to have an impact on the way an organisation operates, the digital twin and the enabling real-time simulation software must be an integrated part of the operating model. Realtime simulation is the essential element of the digital twin concept that builds new capabilities. Therefore, real-time simulation can redefine business processes and impact how information is managed, and IT architecture defined. For successful digital twin implementation, based on real-time simulation, a company must evaluate its; simulation maturity and capabilities, product-service-system maturity and capabilities, and customer lifecycle management maturity. Future research should concentrate on the benefits that the digital twin can create over the complete lifecycle of the product and how machine learning can create new services and for customers and the companies offering them.

\section{References}

1. Mikkola, A., Hannola, L., Handroos, H., Rantanen, H., Ullako, K., 2014, LUT Research Platform on Sustainable Product Processes Through Community-Based Real-Time Simulation, Lappeenranta University of Technology, Lappeenranta, Finland

2. Bilello, P., A., 2017, The Digital Twin has Landed, CIM Data

3. Grieves, M., 2006, Product Lifecycle Management: Driving the next generation of lean thinking, McGraw-Hill, New York.

4. Saaksvuori, A. and Immonen, A., 2008, Product Lifecycle Management, Springer, Berlin.

5. Siller, H., Estruch, A., Vila, C., Abellan, J. \& Romero, F., 2008. Modeling workflow activities for collaborative process planning with product lifecycle management tools. Journal of Intelligent Manufacturing. Volume 19 Issue 6 pp. 689-700.

6. Stark, J., 2018, Product Lifecycle Management (Volume 3): The Executive Summary, Springer International Publishing AG 2018.

7. Cedeño J.M.V., Papinniemi J., Hannola L., Donoghue I., 2018. Developing smart services by internet of things in manufacturing business. LogForum 14 (1), 59-71, http://dx.doi.org/10.17270/J.LOG.2018.268

8. Tukker, A. and Tischner, U. (2006) Product-services as a research field: past, present and future. Journal of Cleaner Production 14 (2006) 1552-1556.

9. Xin, y., Ojanen, V. and Huiskonen J. (2017) Empirical studies on Product-Service Systems - A Systematic Literature Review. Procedia CIRP, 64 (2017) 399-404.

10. Garcia de Jaloj, J., Bayo, E., Kinematic and Dynamic Simulation of Multibody Systems: The Real Time Challenge, 1994, Springer-Verlag

11. Hevner, A., 2007, A Three Cycle View of Design Science Research, Scandinavian Journal of Information Systems, Vol. 19 (2), pp. 87-92.

12. A. Hevner, S. March, J. Park, and S. Ram, 2004, Design Science Research in Information Systems, Management Information Systems Quarterly, Vol. 28, No. 1, March 2004, pp. 75105.

13. Donoghue I, Hannola L., Papinniemi J., 2017, Product Lifecycle Management Framework for Business Transformation, $24^{\text {th }}$ International Conference on Production Research 